\title{
Efeito da suplementação com pupunha como fonte de vitamina A em dieta: estudo em ratos*
}

\section{Effect of supplementation with peach palm as source of vitamin A: study with rats}

\author{
Lucia K.O. Yuyama e Silvia M.F. Cozzolino \\ Instituto Nacional de Pesquisas da Amazônia. Manaus, AM - Brasil (L.K.O.Y.), Departamento de \\ Alimentos e Nutrição Experimental da Faculdade de Ciências Farmacêuticas da Universidade de São \\ Paulo. São Paulo, SP - Brasil (S.M.F.C.).
}

\begin{abstract}
Resumo
Foi estudado o efeito da suplementação com pupunha (Bactris gasipaes H.B.K.), polpa cozida e transformada em farinha, como fonte de vitamina A, em dieta regional de Manaus, AM,Brasil, por meio do ensaio biológico com ratos. A metodologia utilizada foi da depleção dos animais em zinco e vitamina A, seguida da repleção com a dieta regional (DR), DR + pupunha, $\mathrm{DR}$ + vitamina A e dieta controle (DC). A dieta foi elaborada para famílias com rendimentos inferiores a dois salários-mínimos. Foram utilizadas ratas albinas adultas pós-parto, cada qual com 6 filhotes machos, que receberam ração à base de caseína lavada com EDTA a $1 \%$, sem adição de Zn e vitamina A, por 25 dias, com a finalidade de obtenção de animais recém-desmamados deficientes nestes dois nutrientes. $\mathrm{O}$ período de repleção dos animais, recém-desmamados, foi de 30 dias e o delineamento foi inteiramente casualizado com 4 tratamentos de 8 animais cada. A suplementação efetuada seguiu as recomendações do "Committee on Laboratory Animal Diets". Os parâmetros empregados para a avaliação da utilização de vitamina A foram as concentrações de vitamina A no fígado e plasma e o crescimento dos animais. Ao final do experimento, observou-se que os animais que consumiram a ração à base da dieta regional de Manaus, suplementada com pupunha e vitamina A, apresentaram, respectivamente, concentração significativamente maior de vitamina A no fígado, 43,3 $\pm 6,5 \mu \mathrm{g}$ / $\mathrm{g}$ e $42,0 \pm 4,3 \mu \mathrm{g} / \mathrm{g}$ em relação à dieta regional, $5,5 \pm 1,1 \mu \mathrm{g} / \mathrm{g}(\mathrm{p}<0,05)$. A quantidade de zinco presente na dieta regional de Manaus, 10,7 mg diários, foi biodisponível quando avaliada pela concentração de zinco nos fêmures. Os resultados sugerem que existe necessidade de suplementação da dieta regional de Manaus com vitamina A para a manutenção das reservas hepáticas, podendo, para tanto, ser utilizada a fonte natural da pupunha.
\end{abstract}

Pupunha. Suplementação alimentar. Vitamina na dieta.

\footnotetext{
* Parte da Tese de Doutorado, apresentada ao Departamento de Alimentos e Nutrição Experimental da Faculdade de Ciências Farmacêuticas da USP, 1993. Pesquisa financiada pelo Conselho Nacional de Desenvolvimento Científico e Tecnológico (CNPq) - Processo n ${ }^{\circ} 403454 / 90-5$ e pela Fundação de Amparo à Pesquisa do Estado de São Paulo (FAPESP) - Processo no. 90/0991-3.

Correspondência para/Correspondence to: Lucia K.O.Yuyama - Instituto Nacional de Pesquisas da Amazônia (INPA/CPCS) - Al.Cosme Ferreira, 1756, Aleixo - 69083-000 - Manaus, AM, Brasil. E-mail: yuyama@Cr-am.r.n.p.br Edição subvencionada pela FAPESP. Processo 95/2290-6.

Recebido em 13/7/1994. Reapresentado em 27/1/1995. Aprovado em 17/10/1995.
} 


\begin{abstract}
The effect of supplementation with peach palm (Bactris gasipaes H.B.K.), as an alternative source of vit. A, in the regional diet of Manaus, AM, Brazil, in which the pulp was cooked and transformed into flour, was studied. The biological trial involved rats which were depleted in zinc and vitamin A, followed by repletion using the regional diet $(R D), R D$ plus peach palm and $R D$ plus vitamin $A$. The parameters used to determine the utilization of vitamin $A$ were the vitamin A concentrations in the liver and plasma, and the growth of the animals. The diet was prepared according to the data of Shrimpton and Giugliano for families earning less than two legal minimum salaries. Adult post-partum rats were used, with six male pups each, which received a diet based on casein washed with $1 \%$ EDTA, without the addition of zinc or vitamin A for a period of 25 days, for the purpose of obtaining newly-weaned animals which were deficient in $\mathrm{Zn}$ and Vit.A. A control group received a diet also based on casein washed with $1 \%$ EDTA, but with all the nutrients in the quantities suggested by the Committee on Laboratory Animal Diets. The repletion period of the newly-weaned rats was of 30 days and the experimental design was entirely randomized with four groups of eight rats each. The diet supplementation followed the recommendations of the Committee on Laboratory Animal Diets. At the end of the experiment, it was observed that rats which consumed the diet based on the regional diet of Manaus supplemented with either peach palm or vitamin A showed a significantly greater concentration of vitamin A in the liver, $43.3 \pm$ $6.5 \mu \mathrm{g} / \mathrm{g}, 42.0 \pm 4.3 \mu \mathrm{g} / \mathrm{g}$, respectively in relation to the regional diet, $5.5 \pm 1.1$ $\mu \mathrm{g} / \mathrm{g}(\mathrm{p}<0.05)$. The amount of zinc present in the regional diet, $10.7 \mathrm{mg}$ per day, was bioavailable as determined by the concentration of zinc in the femurs. The results suggest that the regional diet of Manaus needs to be supplemented with vitamin A to maintain the hepatic reserves, and that such suplementation can be accomplished with peach palm, an abundant local commodity.
\end{abstract}

Peach palm. Supplementary feeding. Dietary vitamins.

\section{INTRODUÇÃO}

A região Norte do Brasil se caracteriza por uma disponibilidade de frutos ricos em pró-vitamina A, entre eles a pupunha (Bactris gasipaes H.B.K. $)^{1}$, que é um fruto tropical da família das palmáceas, cuja origem é bastante discutida ${ }^{10}$. O fruto representa uma fonte de alimento potencialmente nutritiva pelo seu alto conteúdo de carotenóides biodisponíveis ${ }^{1,31}$.

Portanto, explorar esse fruto deve ser prioridade básica da região, onde já foi comprovada a deficiência de vitamina A. O incentivo quanto ao seu plantio e a educação alimentar da população para o seu consumo, bem como a sua utilização para suplementação ou fortificação de alimentos ou dietas, poderiam solucionar este problema de saúde pública. Por outro lado,não existem relatos de toxicidade ou hipervitaminose resultantes da ingestão excessiva de $B$-caroteno ${ }^{15}$.O aspecto mais significante dos carotenóides, além da cor que eles proporcionam aos alimentos, é o fato de representarem a principal fonte dietética de vitamina A dos países em desenvolvimento?.

A vitamina A circula no plasma, tanto do homem como do animal, na forma de retinol ligado a uma proteína específica, a proteína ligadora de retinol $(\mathrm{RBP})^{3,20}$. A RBP, na forma de um complexo molar 1:1 de RBP-retinol e transtirretina (TTR), faz o transporte de vitamina A para os tecidos periféricos ${ }^{30}$.

A deficiência de vitamina A normalmente não ocorre como um problema isolado, outros fatores devem ser considerados.Entre eles, cita-se a deficiência de proteína, responsável pela biossíntese da proteína ligadora de retinol e transtirretina ${ }^{27}$. Outro fator corresponde à deficiência de zinco, responsável pela síntese da RBP pelo fígado e, conseqüentemente, pela mobilização da vitamina A do fígado para os tecidos periféricos ${ }^{29}$. Por fim, a deficiência de vitamina $\mathrm{A}$, que interfere na secreção da RBP hepática ${ }^{20}$.

Assim, considerando a magnitude da hipovitaminose A na Amazônia ${ }^{18}$ e a deficiência de 
zinco na dieta do amazônida ${ }^{25}$, no presente trabalho foi estudado o efeito da suplementação com pupunha em uma dieta regional de Manaus, AM, como fonte suplementar de vitamina A, e verificado os efeitos em relação ao zinco, na repleção de animais deficientes em zinco e vitamina $\mathrm{A}$.

\section{MATERIAL E MÉTODO}

\section{Pupunha (Bactris gasipaes H.B.K.)}

\section{Obtenção e Processamento}

A pupunha foi obtida do banco de germoplasma da estação experimental de fruticultura do Instituto Nacional de Pesquisa da Amazônia (INPA), situada no km 60 da Br 174, no Município de Manaus, AM. Os frutos foram processados de acordo com os hábitos e costumes regionais, ou seja, cozidos em água e sal a uma temperatura de, aproximadamente, $95^{\circ} \mathrm{C}$. Após cocção, foram removidas casca e semente. A polpa comumente consumida pela população, foi triturada em um liquidificador elétrico, dessecada em estufa com circulação de ar a uma temperatura de $40-45^{\circ} \mathrm{C}$ e transformada em farinha em moinho elétrico, para facilidade de análise e suplementação da ração.

A concentração de vitamina A na pupunha (farinha), utilizando a razão de conversão de $6 \mu \mathrm{g}$ de $\beta$ caroteno para 1 de retinol equivalente, foi de 17,18 RE (retinol equivalente) por grama de amostra.

\section{Dieta}

As rações,simulando a dieta regional de Manaus,foram elaboradas segundo os dados de Shrimpton \& Giugliano ${ }^{25}$, tomando como base o consumo médio de famílias com rendimentos até 2 saláriosmínimos (Tabela 1).

Considerando a concentração de vitamina A na dieta regional de Manaus de 25,8 $\mu \mathrm{g} / 100 \mathrm{~g}$, foram adicionados $94,2 \mu \mathrm{g}$ de Vitamina A, oriunda da farinha de pupunha, e $94,2 \mu \mathrm{g}$ de palmitato de retinila no preparo, respectivamente, da dieta regional suplementada com pupunha (DR+PUP) e da dieta regional suplementada com vitamina A (DR+VIT.A), visando a atender as recomendações de vitamina A preconizadas pelo "Committee on Laboratory Animal Diets" ${ }^{11}$.

\section{Ensaio Biológico}

Foram utilizadas 13 ratas albinas da linhagem Wistar (Rathus norvergicus, var. albinus, rodentia Mammalia), adultas, pós-parto, com 6 filhotes machos cada, provenientes da colônia do biotério da Faculdade de Ciências Farmacêuticas da Universidade de São Paulo. Estas foram mantidas por um período de 25 dias, consumindo uma ração à base de caseína lavada com EDTA a $1 \%$ deficiente em zinco e vitamina A, visando a obtenção de animais recém-desmamados deficientes nestes dois nutrientes. Paralelamente, foi constituído um grupo
Tabela 1 - Composição básica da dieta regional de Manaus, AM. (Shrimpton \& Giugliano ${ }^{25}$ )

\begin{tabular}{lc}
\hline Alimentos & Quantidade per capita (g) \\
\hline Pão & 140,6 \\
Arroz & 64,7 \\
Farinha de mandioca d'água/seca & 71,9 \\
Batata doce/inglesa & 13,3 \\
Açúcar & 60,4 \\
Feijão sul & 29,7 \\
Tomate & 11,5 \\
Cebola & 8,9 \\
Milho verde & 7,1 \\
Jerimum & 3,5 \\
Couve & 2,7 \\
Cheiro verde & 4,7 \\
Banana prata/maçã & 65,2 \\
Abacate & 5,8 \\
Limão & 4,7 \\
Carnes:bovina/galinha & 74,4 \\
Ovos & 12,5 \\
Peixe & 150,6 \\
Leite reconstituído & 101,2 \\
Óleo & 16,0 \\
Margarina & 6,1 \\
Refrigerante & 59,9 \\
Café & 12,4 \\
Sal & 9,8 \\
Condimentos (Coloral, pimenta,vinagre) & 5,1 \\
\hline Total & 943,0 \\
\hline
\end{tabular}

controle, com duas ratas adultas pós parto, com 6 filhotes machos cada, que receberam a ração também à base de caseína lavada com EDTA a 1\%, porém contendo todos os nutrientes nas quantidades sugeridas pelo "Committee on Laboratory Animal Diets ${ }^{11}$ ". A caseína utilizada foi previamente lavada com EDTA a 1\%, por duas vezes, e água desionizada, por dez vezes, para a retirada do zinco residual de $21 \mu \mathrm{g} / \mathrm{g} . O$ teor final obtido foi de $4,98 \mu \mathrm{g} / \mathrm{g}$.

Após a depleção, todos os filhotes, com exceção do grupo controle, receberam a ração à base da dieta regional de Manaus, por um período de 7 dias, para efeito de adaptação,e, logo a seguir, as respectivas rações experimentais por 30 dias. $\mathrm{O}$ grupo-controle recebeu a ração completa à base de caseína. $\mathrm{O}$ delineamento foi inteiramente casualizado, com 4 tratamentos de 8 animais cada, assim distribuídos: Dieta regional (DR), Dieta regional + pupunha (DR + PUP.), Dieta regional + vitamina $\mathrm{A}(\mathrm{DR}+\mathrm{A})$ e Dieta-controle $(\mathrm{DC})$. Durante este período, os animais foram mantidos em gaiolas individuais de aço inoxidável, em ambiente com umidade e temperatura controladas e constantes, com ciclo de luz de $12 \mathrm{~h}$; a água fornecida foi desionizada.

O crescimento dos animais foi acompanhado, durante todo o estudo, por meio de pesagens semanais. A ingestão das rações, a troca de água dos bebedouros e a coleta de fezes foram acompanhadas a cada dois dias no mesmo horário. Houve restrição alimentar apenas no dia do sacrifício. 
Em cada etapa do experimento, 6 animais foram sacrificados para a obtenção do material biológico para as análises.

A análise química das rações, em triplicata, quanto à umidade, cinzas, proteína, extrato etéreo, fração nifext e energia, seguiu as recomendações da "Association of Official Analytical Chemistry" (AOAC) ${ }^{5}$. Para a determinação do teor de carotenóides na farinha de pupunha e na dieta regional de Manaus, seguiu-se a metodologia preconizada por Rodriguez e col. ${ }^{24}$, que consiste na extração dos pigmentos com acetona resfriada e saponificação com KOH $10 \%$ em metanol por uma noite, à temperatura ambiente. Os pigmentos são separados individualmente, utilizando coluna de $\mathrm{MgO}$ : hipho-hiflosupercel (1:1) desenvolvida com concentrações crescentes de acetona em éter de petróleo (1-15\%). Foi considerado apenas o $\beta$-caroteno. A concentração do $\beta$-caroteno foi calculada através dos máximos de absorção e do correspondente valor de absortividade tabelados por Davies ${ }^{14}$.

A razão de conversão de $6 \mu \mathrm{g}$ de $\beta$-caroteno correspondendo a $1 \mathrm{RE}$ (retinol equivalente) estabelecida pela "National Academy of Science" e "National Research Council"(NAS-NRC) ${ }^{21}$, foi utilizada para calcular os valores de vitamina A.

As concentrações de vitamina A e caroteno total, no plasma e fígado dos animais, foram determinadas pelo método proposto por Bessey e col. ${ }^{7}$, modificado por Araújo e Flores ${ }^{4}$.

O teor de zinco nas rações e fêmures foi determinado pelo método espectrofotométrico de absorção atômica, por leitura direta em solução de amostras obtidas por digestão via úmida, de acordo com as normas preconizadas pelo Instituto Adolfo Lutz ${ }^{16}$. Para confiabilidade das análises utilizou-se material de referência, certificado, de acordo com Cornelis ${ }^{12}$.

Para a análise estatística dos resultados, utilizou-se a análise de variância e, para efeito de comparação entre as médias dos tratamentos, o teste de Tukey com 5\% de probabilidade ${ }^{23}$.

\section{RESULTADOS E DISCUSSÃO}

Avaliando o aspecto quantitativo e os fatores extrínsecos ou dietéticos, observa-se que a dieta regional de Manaus apresentou aspectos que favoreceram o aproveitamento da vitamina $\mathrm{A}$, ou seja, alto teor protéico $(96,8 \mathrm{~g} / \mathrm{dia})$ oriundo do peixe e outras fontes de origem animal, valores limítrofes de zinco $(10,7 \mathrm{mg} /$ dia $)$ e deficiência de vitamina A $(126,4 \mu \mathrm{g} / \mathrm{dia})$. Assim, é possível que esses fatores tenham interferido nos resultados obtidos em relação ao nutriente estudado.

No que se refere ao zinco, pode-se considerar que a quantidade presente na dieta foi biodisponível, quando avaliada pela concentração de zinco nos fêmures. Ou seja, os animais que receberam a dieta regional de Manaus apresentaram teores de zinco nos fêmures de 111,7 \pm 7,7 $\mu \mathrm{g} / \mathrm{g}$, DR + PUP de 108,8 \pm $2,9 \mu \mathrm{g} / \mathrm{g}, \mathrm{DR}+\mathrm{Vit}$. A de $116,0 \pm 5,8$ e DC de $98,8 \pm$ $15,2 \mu \mathrm{g} / \mathrm{g}$.

Quanto ao desenvolvimento ponderal: no início do período de repleção, os animais apresentaram peso de 48,9 $\pm 0,5 \mathrm{~g}$. De acordo com a Tabela 2 , verifica-se que os animais submetidos aos diferentes tratamentos ganharam peso, tendo sido mais

Tabela 2 - Médias e desvios-padrão do consumo de ração e ganho de peso dos animais submetidos aos diferentes tratamentos, no período de repleção*

\begin{tabular}{lcc}
\hline $\begin{array}{l}\text { Tratamentos } \\
(\mathrm{n}=8 / \text { grupo })\end{array}$ & $\begin{array}{c}\text { Consumo de ração } \\
(\mathrm{g})\end{array}$ & $\begin{array}{c}\text { Ganho de peso } \\
(\mathrm{g})\end{array}$ \\
\hline DR & $388,3 \mathrm{a} \pm 28,7$ & $135,6 \mathrm{a} \pm 12,7$ \\
DR + PUP. & $404,8 \mathrm{a} \pm 51,4$ & $145,7 \mathrm{a} \pm 21,2$ \\
DR + Vit.A & $390,5 \mathrm{a} \pm 43,4$ & $144,2 \mathrm{a} \pm 23,6$ \\
DC & $303,3 \mathrm{~b} \pm 33,5$ & $99,3 \mathrm{~b} \pm 16,0$ \\
\hline
\end{tabular}

* No sentido vertical, as mesmas letras indicam que os valores não são significativamente diferentes $(p<0,05)$.

DR (Dieta regional).

DR + PUP. (Dieta regional suplementada com pupunha).

$\mathrm{DR}+$ Vit.A (Dieta regional suplementada com vitamina A). DC (Dieta-controle)

pronunciado para os animais alimentados com a dieta regional.

Observa-se que, embora a quantidade de vitamina $\mathrm{A}$, consumida pelos animais submetidos ao tratamento com dieta regional, estivesse abaixo dos índices recomendados, o ganho de peso foi semelhante ao dos animais dos grupos suplementados e superior aos do grupo-controle. Vários fatores interferem no consumo da ração e, conseqüentemente, no ganho de peso dos animais; e mesmo havendo o cuidado quanto a adequação dos nutrientes, existe diferença na composição das rações, isto é, dos alimentos que compuseram a dieta regional de Manaus e da ração à base de caseína, que pode ter interferido no consumo. $\mathrm{O}$ fato da caseína ter sido previamente lavada com EDTA a $1 \%$ poderia ter alterado a palatabilidade e aceitabilidade da mesma, de acordo com os estudos de Cossack e Hamer ${ }^{13}$.

Embora quantitativamente insuficiente em relação às recomendações, podemos supor que a vitamina A da dieta regional foi utilizada e teria contribuído para o ganho de peso dos animais. Entre os fatores predisponentes da biodisponibilidade de vitamina A da dieta regional podemos citar; a fonte protéica de alto valor biológico, favorecendo a síntese das proteínas transportadoras de retinol (Proteína ligadora de retinol e transtirretina) e o crescimento; 
Tabela 3 - Médias e desvios-padrão da concentração total de carotenóides no fígado, e da concentração de vitamina A no plasma e fígado dos animais submetidos aos diferentes tratamentos no período de repleção.*

\begin{tabular}{|c|c|c|c|}
\hline $\begin{array}{l}\text { Tratamentos } \\
(\mathrm{n}=8 / \text { grupo) }\end{array}$ & $\begin{array}{c}\text { Total de carotenóides } \\
\text { fígado }(\mu \mathrm{g} / \mathrm{g})\end{array}$ & $\begin{array}{c}\text { Vit. A no plasma } \\
(\mu \mathrm{g} \%)\end{array}$ & $\begin{array}{c}\text { Vit.A no fígado } \\
(\mu \mathrm{g} / \mathrm{g})\end{array}$ \\
\hline DR & $0,3 b \pm 0,2$ & $26,1 \mathrm{a} \pm 5,4$ & $5,5 c \pm 1,1$ \\
\hline DR + PUP. & $8,3 \mathrm{a} \pm 2,5$ & $24,0 \mathrm{a} \pm 3,4$ & $43,3 a \pm 6,5$ \\
\hline $\mathrm{DR}+$ Vit.A & $0,9 b \pm 0,3$ & $22,7 a \pm 5,4$ & $42,0 \mathrm{a} \pm 4,3$ \\
\hline DC & $1,6 b \pm 0,3$ & $22,4 \mathrm{a} \pm 3,1$ & $14,2 b \pm 3,0$ \\
\hline
\end{tabular}

* No sentido vertical, as mesmas letras indicam que os valores não são significantemente diferentes $(\mathrm{p}<0,05)$.

DR (Dieta regional)

DR + PUP. (Dieta regional suplementada com pupunha).

DR + Vit.A (Dieta regional suplementada com vitamina A)

DC (Dieta-controle)

o teor de lipídios adequado ao animal, carreador essencial das vitaminas lipossolúveis, entre elas a vitamina $\mathrm{A}$; e a concentração de zinco próxima à necessidade do animal, nutriente essencial para o crescimento e síntese da proteína ligadora de retinol (RBP). Assim, pode-se considerar que, ao lado desses fatores mencionados, a concentração de vitamina A na dieta regional, mesmo abaixo das recomendações, pode proporcionar crescimento normal nos animais em desenvolvimento, ao lado de aporte energético adequado.

A concentração total de carotenóides, no fígado dos animais do grupo DR + PUP, foi significativamente maior do que nos demais tratamentos,e de acordo com estudos anteriores ${ }^{31}$ (Tabela 3 ).

Quando os ratos são alimentados com altos níveis de B- caroteno, a eficiência da conversão em retinol é reduzida ${ }^{6}$ e, quando comparados com o ser humano, os roedores de modo geral absorvem pouco Bcaroteno intacto $^{8}$, a menos que alimentados em quantidades substanciais ${ }^{19}$. A eficiência na quebra dos carotenóides está em relação direta com os níveis de carotenóides plasmáticos e teciduais. O intestino do rato tem uma enzima muito eficiente para a quebra da cadeia do B-caroteno,sendo responsável pelos níveis reduzidos de carotenóides plasmáticos. No homem, esta enzima nao é tão eficiente e, então, alguns carotenóides podem ser encontrados no plasma ou depositados no fígado ou em outros órgãos ${ }^{26}$.

A suplementação com pupunha visou a atender as recomendações de vitamina A,segundo a Recommended Dietary Allowance (RDA), e embora se tenha encontrado concentração significativa de carotenóides no fígado dos animais suplementados com pupunha, houve um suprimento de vitamina A pela pupunha,tanto quanto de vitamina A préformada, quando avaliado pelas reservas hepáticas de vitamina A (Tabela 3). A concentração total significativa de carotenóides no fígado dos animais pode ser decorrente da substimação ao se determinar apenas $B$-caroteno .

Tem sido relatado que, no salmão, o transporte do ß-caroteno absorvido é feito por lipoproteína de baixa densidade ${ }^{2}$. Entretanto, o mecanismo de captação, de estocagem e de transporte de $\beta$-caroteno intacto, pelos tecidos de mamíferos, não é totalmente entendido. Um complexo de carotenóides e proteínas tem sido caracterizado no homogenado de fígado de ratos Wistar, alimentados com $0,2 \%$ de $\beta$-caroteno, sugerindo que tal complexo pode estar envolvido na estocagem e/ou transporte do ßcaroteno $^{22}$. Em relação à concentração plasmática de vitamina $A$, não houve diferença significativa entre os tratamentos (Tabela 3) indicando que os teores de zinco foram suficientes para manter os níveis plasmáticos, por meio do seu efeito específico sobre a mobilização de vitamina A hepática, conforme os estudos de Smith e col. ${ }^{28}$ Dados da literatura indicam que a concentração de vitamina A no plasma está diretamente relacionada com a concentração de vitamina A no fígado somente quando o estoque hepático estiver abaixo do limiar ${ }^{17}$, achados semelhantes sugerem que na inadequação dietética de vitamina A, como observado no presente estudo, existe mecanismo de compensação interna que mantém os níveis plasmáticos em uma concentração necessária para suprir os tecidos a um nível ideal ${ }^{4}$.

Os níveis hepáticos de vitamina A foram significativamente maiores nos animais cuja ração à base da dieta regional de Manaus foi acrescida de pupunha ou vitamina A, confirmando assim a eficiência da utilização da pupunha como fonte de vitamina A. As observações no animal experimental sugerem que o valor encontrado de vitamina A na dieta regional de Manaus seja limitante para o ser humano. 


\section{REFERÊNCIAS BIBLIOGRÁFICAS}

1. AGUIAR, J.P.L.; MARINHO, H.A.; REBELO, Y.S.; SHRIMPTON, R. Aspectos nutritivos de alguns frutos da Amazônia. Acta Amazôn., 10:755-8, 1980.

2. ANDO, S. \& HATANO, M. Isolation of apolipoproteins from carotenoid carrying lipoprotein in the serum of chum salmon on corhynchusketa. J. Lipid Res., 29:1264-71,1988.

3. APGAR, J. Mobilization of vitamin A by the zinc deficient rat. Nutr. Rep. Int., 15:553-9, 1977.

4. ARAÚJO, C.R.C. \& FLORES, H. Improved Spectrophotometric vitamin A assay. Clin. Chem., 24:1-386,1978.

5. ASSOCIATION OF OFFICIALANALYTICAL CHEMISTS. Official methods of analysis. 14. ed. Arlington, 1984.

6. BEN-AMOTZ; MOKADY, S.; AURON, M. The B-carotene rich alga Dunaliela bardawil as a source of retinol in a rat diet. Br. J. Nutr., 54:443-9, 1988.

7. BESSEY, O.A.; LOWRY, O.H.; BROCK, M.F.; LOPEZ, J.A. The determination of vitamin A and carotene in small quantities of blood serum J. Biol. Chem., 166:177-9, 1946.

8. BONDI, A. \& SKLAN, D. Vitamin A and carotene in animal nutrition. Prog. Food Nutr. Sci., 8:165-91, 1984.

9. BRUBACKER, G.B. \& WEISER, H. The vitamin A activity of beta carotene. Int.J. Vitam. Nutr. Res., 55:5-15,1985.

10. CAMACHO, V.E. El pejibaye (Guilielma gasipaes H.B.K.) IICA. Turrialba, 1972.

11. COMMITTEE ON LABORATORY ANIMAL DIETS/ ASSEMBLY OF LIFE SCIENCES NATIONAL RESEARCH COUNCIL. Control of diets in laboratory animal experimentation. Nutr. Abstr. Rev., 49:413-9, 1979.

12. CORNELIS, R. Use of references materials in trace element analysis of foodstuffs. Food Chem., 43:307-13,1992.

13. COSSACK, Z.T. \& Van Den HAMER, C.J.A. Evaluation of the EDTA washed diet for use in the experimental production of zinc deficiency in human subjects. Int. J. Vit. Nutr. Res., 57: 99-102, 1987.

14. DAVIES, B.H. Carotenoids. In: Goodwin, T.W., ed. Chemistry and biochemistry of plant pigments. $2 \mathrm{nd} \mathrm{ed}$. London, Academic Press, 1976. v.2, cap. 19, p. 38-165.

15. HATHCOCK, J.N.; HATTAN, D.J.; JENKINS, M.Y.; MCDONALD, J.T.; SUNDARESAN, P.R.; WIKENING, V.L. Evaluation of vitamin A toxicity. Am. J. Clin. Nutr., 52:183-202, 1990

16. INSTITUTO ADOLFO LUTZ. Normas analíticas do Instituto Adolfo Lutz. 3. ed., São Paulo, 1985.

17. LEWIS, J.M.; BODANSKY, K.G.; MCGUIRE,G. Vitamin $A$ requeriments in the rat. The relation of vitamin $A$ intake to growth and to concentration of vitamin $\mathrm{A}$ in the blood plasma, liver and retinol. J. Nutr., 23:351-63, 1942.
18. MARINHO, H.A.; CASTRO, J.S.; BURINI, R.C. Níveis séricos de vit. A em pré-escolares de um bairro pobre de Manaus, AM. Acta Amazôn., 19:335-42, 1989.

19. MATHEWS-ROTH, M.M. The carotenoid content of various organs of animals admnistered larg amounts of beta carotene. Nutr. Rep. Int., 117:419-23, 1977.

20. MUTO, Y. \& GOODMAN, D.S. Vitamin A transport in rat plasma. J. Biol. Chem., 247:2533-41, 1972.

21. NAS-NRC. National Academy of Science/National Research Council. Recommended dietary allowances. 9 th ed., Washington, 1980, p. 55-71.

22. OKOH, C.; MYCHKOUSKY, I.; LAKSHMAN, M.R. Isolation and some properties of a carotenoid protein complex from rat liver. J. Nutr. Biochem. 4:569-75, 1993.

23. PIMENTEL GOMES, F. Curso de estatística experimental. 12. ed. Piracicaba, 1987

24. RODRIGUEZ, D.B.; RAYMUNDO, L.C.; TUNG-CHENG LEE, SIMPSON, K.L.; CHICHESTER, C.O. Carotenoid pigment changes in ripening monordica charantia fruits. Ann. Bot., 40:615-24, 1976.

25. SHRIMPTON, R. \& GIUGLIANO, R. Consumo de alimentos e alguns nutrientes em Manaus, 1973-74. Acta Amazôn., 9:117-41, 1979.

26. SIMPSON, K.L. Relative value of carotenoids as precursors of vitamin A. Proc. Nutr. Soc., 42:7-17, 1983.

27. SMITH, F.R.; GOODMAN, D.S.; ZAKLAMA, M.S.; BABR. M.K.; MARAGHY, S.; PTWARDHAN, V.S. Serum vitamin A, retinol-binding protein and prealbumin concentrations in protein-calorie malnutrition. I. A functional defect in hepatic retinol release. Am. J. Clin. Nutr., 26:973-81, 1973 b.

28. SMITH, J.C.Jr.; MCDANIEL, E.G.; FAN, F.F.; HALSTED, J.A. Zinc: a trace elements essential in vitamin A metabolism. Science, 181: 954-5, 1973.

29. SMITH, J.E.; BROWN, E.D.; SMITH, J.C.Jr. The effects of zinc deficiency on the metabolism of retinol-binding protein in the rat. J. Lab. Clin. Med., 84:692-7, 1974.

30. SOPRANO, D.R.; SOPRANO, K.J.; GOODMAN, D.S. Retinol-binding protein messenger, RNA levels in the liver and extrahepatic tissues of the rat. J. Lipid. Res., 27: 166-71, 1986.

31. YUYAMA, L,K.O.; FÁVARO, R.M.D.; YUYAMA, K.; VANNUCCHI, H. Bioavailability of vitamin A from peach palm (Bactris gasipaes H.B.K.) and mango (Mangifera indica L.) in rats. Nutr. Res., 11:1167-75, 1991. 